\title{
Anti-Cancer Drug Screening Based on a Adipose-Derived Stem Cell/ Hepatocyte 3D Printing Technique
}

Xinru Zhao', Siqi Du', Lei Chai', Yufan Xu1', Libiao Liu', Xinwei Zhou', Jiayin Wang', Weiming Zhang', Cheng-Hsien Liu², Xiaohong Wang ${ }^{1,3 *}$

${ }^{1}$ Center of Organ Manufacturing, Department of Mechanical Engineering, Tsinghua University, Beijing, P.R. China

${ }^{2}$ National Tsing Hua University, Department of Power Mechanical Engineering, Hsinchu, Taiwan

${ }^{3}$ State Key Laboratory of Materials Processing and Die and Mould Technology, Huazhong University of Science and Technology, Wuhan, P.R. China

\begin{abstract}
Background: During the last several decades, drug screening results based on two-dimensional (2D) cell cultures could hardly be duplicated by animal experiments due to different cell growth environments. With the development of three-dimensional printing (3DP) techniques, in vitro 3D cell cultures show great advantages in many areas. In this study, a 3D drug screening model based on a cell-laden gelatin/alginate/fibrinogen hydrogel was established using a cell 3D printer developed in Tsinghua University.

Methods: 2D and 3D drug screening effects were compared with three anti-liver tumor drugs (i.e. astragalus polysaccharide, 5-Fluorouracil and matrine). Cell survival rates were tested using 3-[4,5-dimethylthiazol-2-yl]-2,5diphenyl tetra-sodium bromide colorimetric and cell counting kit-8 methods. Some other detection methods, such as 4',6-diamidino-2-phenylindole/5- or 6-(N-Succinimidyloxycarbonyl)-3',6'-O,O'-diacetylfluorescein staining, acridine orange/propidium iodide staining, hematoxylin-eosin staining and scanning electron microscope, were applied to assist the analyses.
\end{abstract}

Results: Cell viability of the 3D adipose-derived stem cell/hepatocyte cocultures was increased. The 3D model enhanced the drug-resistance of hepatocytes.

Conclusion: This in vitro 3D model has promise to be widely used in drug screening.

Keywords: Cell assembly; Drug screening; Adipose-derived stem cells; Hepatocyte; Gelatin/alginate/fibrinogen hydrogel

\section{Introduction}

Since the 1990s, the development of new drugs mainly relies on biological detection platforms that are based on molecular and cellular levels [1]. The greatest feature of these platforms is in vitro two-dimensional (2D) cell cultures. Consequently, the drug screening results achieved using $2 \mathrm{D}$ cultures have little effect on the vast majority of animals [1]. Especially in the human body many different cell types work in a well-organized way, which is hard to be simulated by $2 \mathrm{D}$ cell cultures. It is found that some environmental factors, such as oxygen concentration and temperature, influence the cell growth states, which makes the in vitro simulation particularly challenging.

Recently, a series of new cell culturing techniques, such as optical tweezers [2] and laser-direct writing [3], emerged due to the combination and integration of life science with manufacturing and information technologies. The most obvious disadvantage of these techniques is the difficulty to accurately define and arrange multiple cell types in one construct. 3D printing (3DP), also known as additive manufacturing (AM) or rapid prototyping (RP), is a family of techniques that are able to process nearly all different material systems with computer aided design (CAD) models which are based on object separation-accumulation principles [4]. Especially, biological materials, like cells and cell growth factors, can accurately be put on target positions with quick response speed and high formation precision [57]. Several research groups have transformed a variety of RP techniques from industry towards biological laboratory to assemble or print cells under the instructions of CAD models. For example, in Harvard Medical School, a quasi 3D structure including collagen hydrogel, fibroblasts and keratinocytes was printed [8], whereas in University of Cornell a 3D direct-write printing technology was created [9]. In our former studies, a series of cell assembling [10-19] and low temperature deposition manufacturing technologies [20-25] were produced, which are prominent in complex organ manufacturing and high throughput drug screening areas [26-31].

In the present study, we used our cell printing technique to mimic the hepatic lobule structure instead of 2D cell cultures for drug screening. A gelatin/alginate/fibrinogen hydrogel was selected as the extracellular matrix (ECM) to load cells. Hepatocytes were printed separately or together with adipose-derived stem cells (ADSCs) of a SpragueDawley (SD) rat following a grid structure. In order to compare the difference between 2D and 3D cell cultures, 3-[4, 5-dimethylthiazol2-yl]-2, 5-diphenyl tetrasodium bromide (MTT) colorimetric and the cell counting kit-8 (CKK-8) methods were used to detect cell viabilities under different anti-cancer drugs, such as astragalus polysaccharide (AP), 5-Fluorouracil (5-FU) and matrine. A series of other biological characterization methods, such as hematoxylin-eosin (HE) staining and acridine orange (AO)/propidium iodide (PI) staining were used for a better understanding of the micro structures and interactions between the hepatocytes and ADSCs.

\section{Materials and Methods}

\section{Hepatocytes and adipose-derived stem cells}

A new born SD rat (120 g), male, bought from the Laboratory

*Corresponding author: Xiaohong Wang, Department of Mechanical Engineering Tsinghua University, Beijing 100084, P.R. China, Tel: +86-10-62773202 ; E-mail: wangxiaohong@tsinghua.edu.cn

Received February 11, 2015; Accepted April 06, 2015; Published April 08, 2015

Citation: Zhao X, Du S, Chai L, Xu Y, Liu L, et al. (2015) Anti-Cancer Drug Screening Based on a Adipose-Derived Stem Cell/Hepatocyte 3D Printing Technique. J Stem Cell Res Ther 5: 273. doi:10.4172/2157-7633.1000273

Copyright: ( 2015 Zhao X, et al. This is an open-access article distributed unde the terms of the Creative Commons Attribution License, which permits unrestricted use, distribution, and reproduction in any medium, provided the original author and source are credited. 

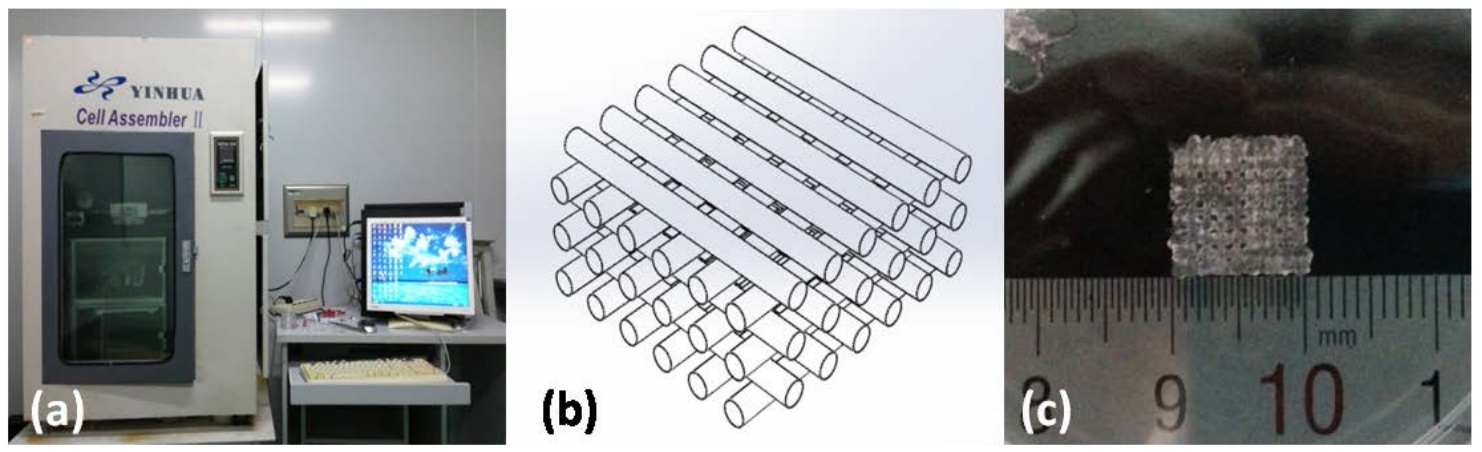

Figure 1: The cell printing machine (a), a computer-aided designed model (b), and a grid 3D cell-laden construct (c).

Animal Center, Medical Department of Beijing University (approved by the Ministry of Health) was used for the cell separation. The hepatocytes were extracted by infusing the rat liver with a $0.1 \%$ type II collagenase (sigma, Aldrich Company, USA) solution [10,11]. Neutralized cell suspension was centrifuged at a speed of $600 \mathrm{r} / \mathrm{min}$ for $5 \mathrm{~min}$ to get the hepatocytes.

Epididymal adipose tissues from the same rat were excised, washed sequentially in serial dilutions of betadine, and then finely minced in a calcium-free phosphate-buffered saline (PBS) (pH 7.2). The mashed tissues were digested in the $0.1 \%$ type II collagenase at a temperature of $37^{\circ} \mathrm{C}$ for $45 \mathrm{~min}$. Neutralized cells were centrifuged to separate the mature adipocytes from the stromal vascular fraction. The floating adipocytes were removed and pelleted. The stromal cells were filtered through a $100 \mu \mathrm{m}$ cell strainer before seeding. ADSCs were cultured in Dulbecco's modified Eagle's medium (DMEM) (Gibco, Paisley, UK), containing $10 \%$ fetal bovine serum (FBS) (Gibco, Paisley, UK) at $37^{\circ} \mathrm{C}$ in an atmosphere of $5 \% \mathrm{CO}_{2}$. Cells were grown to subconfluence and passaged using a standard trypsinization method.

\section{Gelatin/alginate/fibrinogen hydrogel}

Based on the former research of our laboratory, a mixture of gelatin, sodium alginate and fibrinogen was chosen to be the extracellular matrix (ECM) considering biological compatibility, mechanical behavior and economic factors. The gelatin (Tianjin Green-Island Company, China) was dissolved in calcium-free PBS to form $20 \%$ and $10 \%(\mathrm{w} / \mathrm{v})$ solutions. Sodium alginate (Sigma, Aldrich Company, USA) was dissolved in calcium-free PBS to form $4 \%(\mathrm{w} / \mathrm{v})$ solution. The gelatin and sodium alginate solutions were pasteurized three times at $72^{\circ} \mathrm{C}$ for $20 \mathrm{~min}$. Fibrinogen and thrombin (Sigma St. Louis, MO, USA) were dissolved in fetal bovine serum (FBS) free Dulbecco's modified Eagle's medium (DMEM) (GIBCO, USA) to form a $5 \%(\mathrm{w} / \mathrm{v})$ solution. Two concentrations of gelatin and sodium alginate mixtures in a fibrinogen solution were used for cell printing. One was $20 \%(\mathrm{w} / \mathrm{v})$ gelatin, $4 \%$ $(\mathrm{w} / \mathrm{v})$ sodium alginate and $5 \%(\mathrm{w} / \mathrm{v})$ fibrinogen. The other was $10 \%$ $(\mathrm{w} / \mathrm{v})$ gelatin, $4 \%(\mathrm{w} / \mathrm{v})$ sodium alginate and $5 \%(\mathrm{w} / \mathrm{v})$ fibrinogen. Both mixtures consisted of the same ratio between gelatin:alginate:fibrinog en $=2: 1: 1(\mathrm{v} / \mathrm{v} / \mathrm{v})$.

\section{Controlled cell-laden gelatin/alginate/fibrinogen hydrogel printing and stabilization}

The used cell printer is shown in Figure la and the printing process in Figure 2. A grid 3D structure of $10 \mathrm{~mm} \times 10 \mathrm{~mm} \times 5 \mathrm{~mm}$ was designed as shown in Figure 1b. Hepatocytes were printed separately in the gelatin/alginate/fibrinogen hydrogel at a density of $1 \times 10^{7}$ cells/ $\mathrm{ml}$ or as a mixture with ADSCs $\left(1 \times 10^{6}\right.$ cells $\left./ \mathrm{ml}\right)$. The printed construct is shown in Figure 1c. After being printed, the construct was stabilized with a $5 \%(\mathrm{w} / \mathrm{v}) \mathrm{CaCl}_{2}$ solution and a $5 \%(\mathrm{w} / \mathrm{v})$ thrombin solution separately for $5 \mathrm{~min}$ in order to crosslink the alginate and to polymerize the fibrinogen molecules.

\section{Scanning electron microscope observation}

After 7 days in vitro culture, some of the samples were fixed in $2.5 \%$ glutaraldehyde at $4^{\circ} \mathrm{C}$ for at least $2 \mathrm{~h}$ before they were dehydrated in a series of ethanol $(50 \%, 70 \%, 80 \%, 90 \%$ and $100 \%)$ solutions and a mixture of half alcohol and half tert-butyl alcohol for $10 \mathrm{~min}$. At last the samples were soaked in tert-butyl alcohol, stored under $-20^{\circ} \mathrm{C}$, freeze-dried and observed using a scanning electron microscope (SEM, Hitachi S-450, Japan).

\section{HE Staining}

After 7 days in vitro culture, some of the 3D constructs were firstly fixed in $4 \%$ paraformaldehyde overnight, embedded in optimum cutting temperature compound (OCT), frozen and sliced to $14 \mu \mathrm{m}$ sections. Then the sections were air dried, fixed with cold acetone, washed with PBS for three times, stained with haematine for 5-10 min, and placed

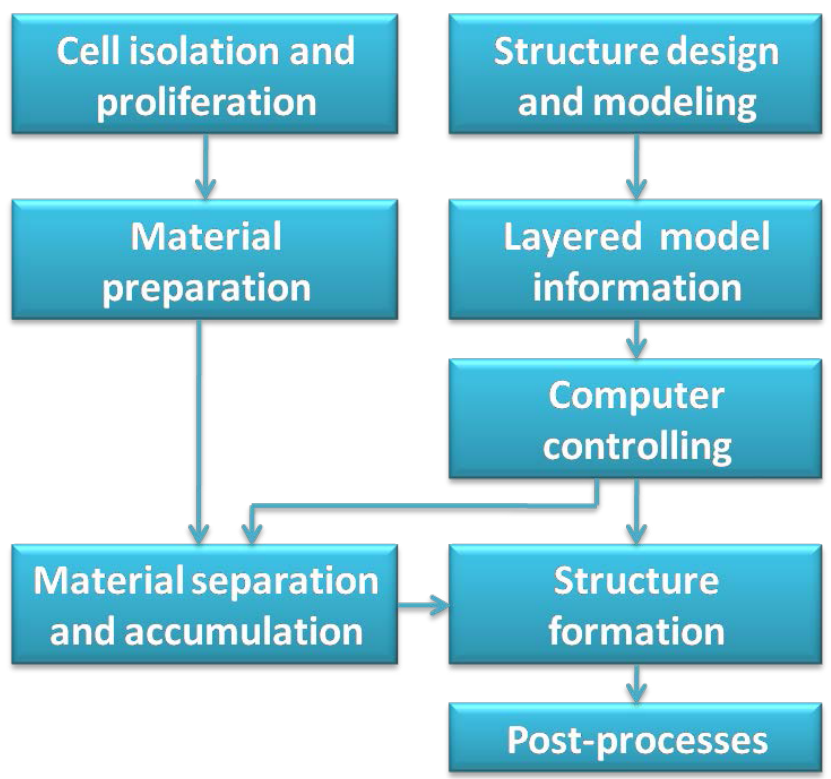

Figure 2: Flow diagram of the cell printing process. 
Citation: Zhao X, Du S, Chai L, Xu Y, Liu L, et al. (2015) Anti-Cancer Drug Screening Based on a Adipose-Derived Stem Cell/Hepatocyte 3D Printing Technique. J Stem Cell Res Ther 5: 273. doi:10.4172/2157-7633.1000273

Page 3 of 10

in concentrated ammonia for $2 \mathrm{~s}$ (for the colored nuclei). Finally, the sections were stained in eosin for $1 \mathrm{~min}$, soaked in $70 \%, 80 \%, 90 \%, 95 \%$ (2 times), 100\% (3 times) alcohol respectively for $1 \mathrm{~min}$, washed with xylene 3 times, and observed under a microscope. Nucleus appeared in purple and cytoplasm in red color.

\section{4',6-diamidino-2-phenylindole (DAPI)/ 5- or6-(N- Succinimidyloxycarbonyl)-3',6'-O,O'-diacetylfluorescein (CFSE) staining}

Before cell printing, the concentrations of the hepatocyte and ADSC suspensions were adjusted to $1 \times 10^{7}$ cells $/ \mathrm{ml}$ and $1 \times 10^{6}$ cells/ $\mathrm{ml}$, respectively. $100 \mu \mathrm{l}$ DAPI $(1 \mu \mathrm{g} / \mathrm{ml})$ was added to $1 \mathrm{ml}$ of the ADSC suspension and $40 \mu \mathrm{l} \mathrm{CFSE} \mathrm{was} \mathrm{added} \mathrm{to} 1 \mathrm{ml}$ of the hepatocyte suspension. The hepatocyte and hepatocyte/ADSC suspensions were placed in a $37^{\circ} \mathrm{C}$ incubator for $15-20 \mathrm{~min}$. After the cell suspensions were centrifugated, the supernatant liquid was removed, and the precipitated cells were washed with PBS 3 times before they were printed with the prepared gelatin/alginate/fibrinogen hydrogel. After 7 days in vitro culture, the samples were examined using a Zeiss laser scanning confocal microscope (LSCM710). The excitation/emission wavelength for DAPI and CFSE staining were $340 \mathrm{~nm} / 488 \mathrm{~nm}$ and 490 $\mathrm{nm} / 530 \mathrm{~nm}$, respectively.

\begin{tabular}{|l|c|c|c|}
\hline & $\begin{array}{c}\text { High concentration } \\
\text { (H) }\end{array}$ & $\begin{array}{c}\text { Middle concentration } \\
\text { (M) }\end{array}$ & $\begin{array}{c}\text { Low concentration } \\
\text { (L) }\end{array}$ \\
\hline AP & $4 \mathrm{mg} / \mathrm{ml}$ & $400 \mu \mathrm{g} / \mathrm{L}$ & $40 \mu \mathrm{g} / \mathrm{L}$ \\
\hline $5-\mathrm{FU}$ & $500 \mu \mathrm{g} / \mathrm{ml}$ & $50 \mu \mathrm{g} / \mathrm{ml}$ & $5 \mu \mathrm{g} / \mathrm{ml}$ \\
\hline Matrine & $1.5 \mathrm{mg} / \mathrm{ml}$ & $0.15 \mathrm{mg} / \mathrm{ml}$ & $15 \mu \mathrm{g} / \mathrm{ml}$ \\
\hline
\end{tabular}

AP: Astragalus Polysaccharide; 5-FU: 5-Fluorouracil

Table 1: Three groups of drug concentrations for screening experiments.

\section{Drug screening}

After the 3D constructs were cultured in 24-well petri dishes for one week, three drugs, AP (Bio-medical Assay), 5-FU (Sigma) and matrine (Santa Cruz), were added to the culture medium in three different concentrations according to our former experiences: high concentration (H) AP $4 \mathrm{mg} / \mathrm{ml}, 5-\mathrm{FU} 500 \mu \mathrm{g} / \mathrm{ml}$, matrine $1.5 \mathrm{mg} / \mathrm{ml}$, middle concentration (M) AP $400 \mu \mathrm{g} / \mathrm{L}$, 5-FU $50 \mu \mathrm{g} / \mathrm{ml}$, matrine 0.15 $\mathrm{mg} / \mathrm{ml}$, and low concentration (L) AP $40 \mu \mathrm{g} / \mathrm{L}, 5$-FU $5 \mu \mathrm{g} / \mathrm{ml}$, matrine $15 \mu \mathrm{g} / \mathrm{ml}$, for 1 to 4 days. The three concentrations of the three drugs are listed in Table 1. Hepatocytes cultured directly on 2D 96-well petri dishes with the same initial cell density as the $3 \mathrm{D}$ constructs and the same drugs were set as a positive control. Untreated $2 \mathrm{D}$ plates and $3 \mathrm{D}$ cultures were set as negative controls. CCK- 8 was used to measure the cell proliferation rate and drug screening effects of the $2 \mathrm{D}$ cultures while a MTT colorimeter was used for the $3 \mathrm{D}$ cultures.

MTT colorimetric measurement: after the cells were exposed to the drugs for different durations, $100 \mu$ of MTT staining solution was added to the 24 -well plates with the $3 \mathrm{D}$ samples before incubating them at $37^{\circ} \mathrm{C}$ for $4 \mathrm{~h}$. The liquid was then removed and $500 \mu \mathrm{l}$ DMSO was added. The culture plate was rolled $10 \mathrm{~min}$ in a shaking table at room temperature. $150 \mu$ of the liquid in each well was transferred to a 96-well. The optical density (OD) of each well was measured at $490 \mathrm{~nm}$ wavelength using a Bio-Rad 550 reader (Japan). The ratio of experimental and control groups represents the relative survival rates of the cells.

CCK-8 measurement: $100 \mu \mathrm{l}$ DMEM and $10 \mu \mathrm{l} \mathrm{CCK-8} \mathrm{solution}$ were added to each well of the 96-well plate with the $2 \mathrm{D}$ samples. Subsequently the plate was put to a carbon dioxide incubator for $4 \mathrm{~h}$. The OD of each well was measured at $450 \mathrm{~nm}$ using the above mentioned Bio-Rad 550 reader. The ratio of experimental and control groups again represents the relative survival rates of the cells.

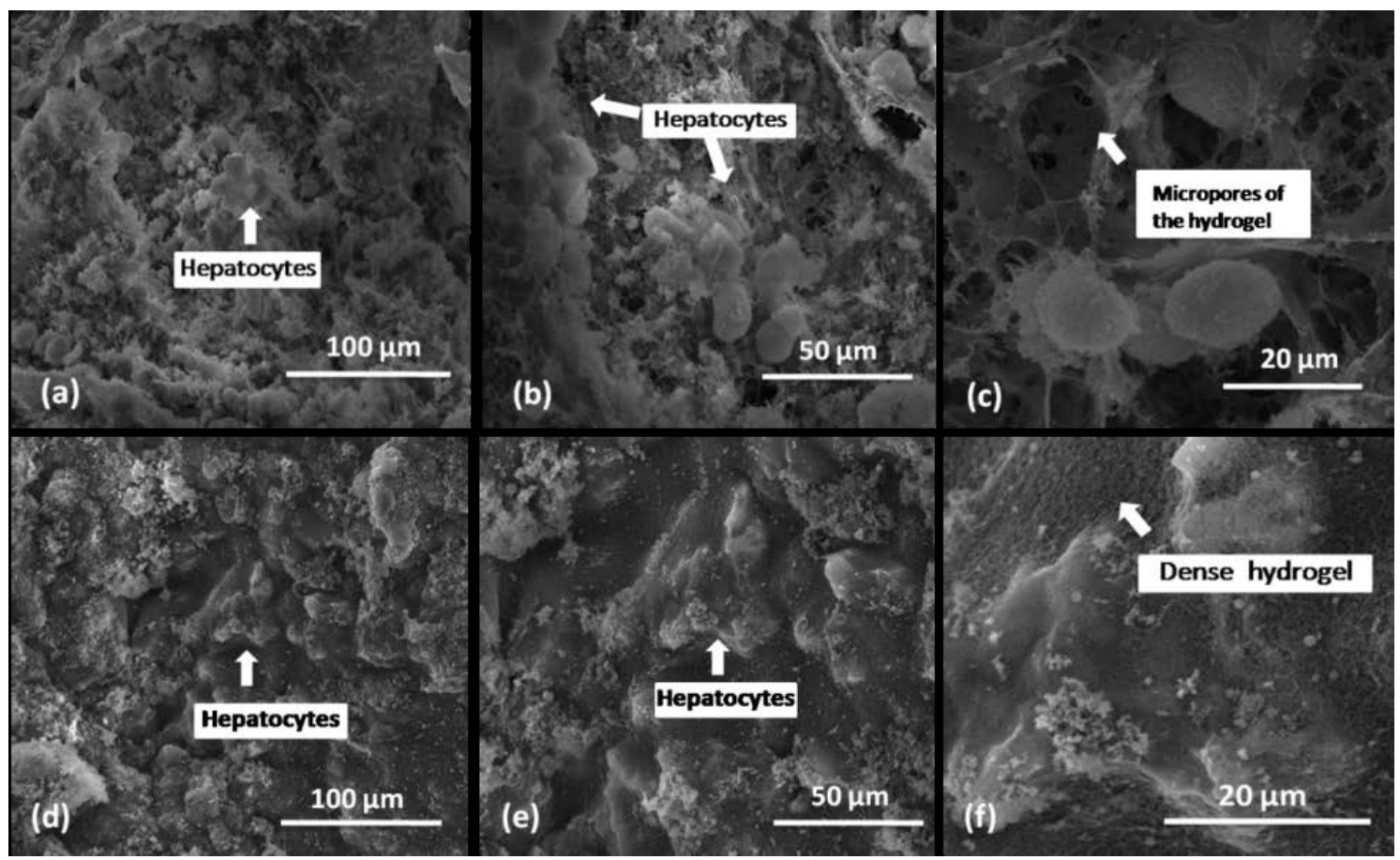

Figure 3: SEM images of hepatocytes in the 3D constructs with different concentrations of gelatin in the gelatine/alginate/fibrin hydrogel $1 \mathrm{~h}$ after the $3 \mathrm{D}$ printing: (a)(c) $10 \%$ (w/v) gelatin in the gelatine/alginate/fibrin hydrogel with different magnifications; (d)-(f) $20 \%$ (w/v) gelatin in the gelatine/alginate/fibrin hydrogel with different magnifications. 


\section{Acridine orange /propidium iodide staining}

After being exposed to the drugs for 1-4 days, both the 2D and 3D samples were stained with acridine orange/propidium iodide (AO/PI) fluorescence. $0.01 \mathrm{ml}$ of $\mathrm{AO}$ solution $(670 \mu \mathrm{mol} / \mathrm{L} \sim 0.3 \mathrm{mg} / \mathrm{L})$ and $1 \mathrm{ml} \mathrm{PI}$ solution $(750 \mu \mathrm{mol} / \mathrm{L} \sim 0.5 \mathrm{mg} / \mathrm{L})$ were added to the 24 -well plate with the samples before they were put in a $37^{\circ} \mathrm{C}$ incubator for $10 \mathrm{~min}$. After being washed by PBS for several times the samples were examined using the LSCM. The emission wavelength of AO is $530 / 640 \mathrm{~nm}$ and PI is $615 \mathrm{~nm}$.

\section{Statistical analysis}

Sample values were expressed as means \pm standard deviation (SD). Unpaired Student's t-test was used to compare the differences between the 2D/3D groups or different culture days. SPSS version 13.0 statistic software (SPSS, Chicago, IL, USA) was used to analyse the values. $\mathrm{P}$-values $<0.05$ were considered significant.

\section{Results}

Effect of low and high gelatin concentrations on morphology of cells laden in the gelatin/alginate/fibrinogen hydrogel

Some SEM images of the 3D constructs with $10 \%(\mathrm{w} / \mathrm{v})$ low and $20 \%(\mathrm{w} / \mathrm{v})$ high gelatin concentrations are shown in Figure 3. The interconnected go-through pores (channels) were predefined by the CAD model to achieve a larger contact area between the medium and the assembled cell. During the printing stage, gelatin played an important role in the sol-gel transformation of the gelatin/alginate/ fibrinogen hydrogel and the stabilization of the printed constructs. With the crosslinking and polymerization of the alginate and fibrinogen molecules, the printed 3D constructs remained stable without collapsing during the long-term in vitro culture. It was found that the gelatin concentration had significant effect on the microstructures of the $3 \mathrm{D}$ constructs. In the low concentration group, there were abundant micro-pores in the printed gelatin/alginate/fibrinogen filaments with diameters ranging from $5 \mu \mathrm{m}$ to $30 \mu \mathrm{m}$. These micro-porous were beneficial for nutrient and metabolic substance transportation in the hydrogel, supplying the embedded cells with adequate nutrition and oxygen. In contrast, in the high concentration group the thick gelatin/ alginate/fibrinogen hydrogel appeared in sheet like shapes. After 7 days culture, most of the hepatocytes were still wrapped by a dense layer of gelatin/alginate/fibrinogen matrix and were separated from each other (Figures 3d, 3e and 3f). From the comparison of these two groups, we can conclude that in the low concentration group, cell shapes were more distinctive than those in the high concentration group. It is easier for the cells in the low concentration matrix to form connections.

\section{HE staining results of hepatocytes and ADSCs/hepatocytes in the gelatin/alginate/fibrinogen hydrogel}

HE staining results of the hepatocyte and ADSC/hepatocyte containing 3D constructs are shown in Figures 4a-4d. After 7 days in vitro culture, many of the cells were in division states with double nuclei. HE staining results containing both hepatocytes and ADSCs are shown in Figures $4 \mathrm{e}-4 \mathrm{~h}$. It is hard to distinguish the hepatocytes and ADSCs from colors. The main differences of the two cell types are shape and size. Most of the hepatocytes have elongated round or elliptical shapes with an average diameter of $\sim 15 \mu \mathrm{m}$. Most of the ADSCs are round with an average diameter of $6 \mu \mathrm{m}$, which is much smaller than those of the hepatocytes. In the marked area of Figure $4 \mathrm{f}$ (by a black oval), cell connections are much clearer than anywhere else where the gelatin/ alginate/fibrinogen matrix is prominent. This result indicates that the thick gelatin/alginate/fibrinogen hydrogel encapsulates the cells and
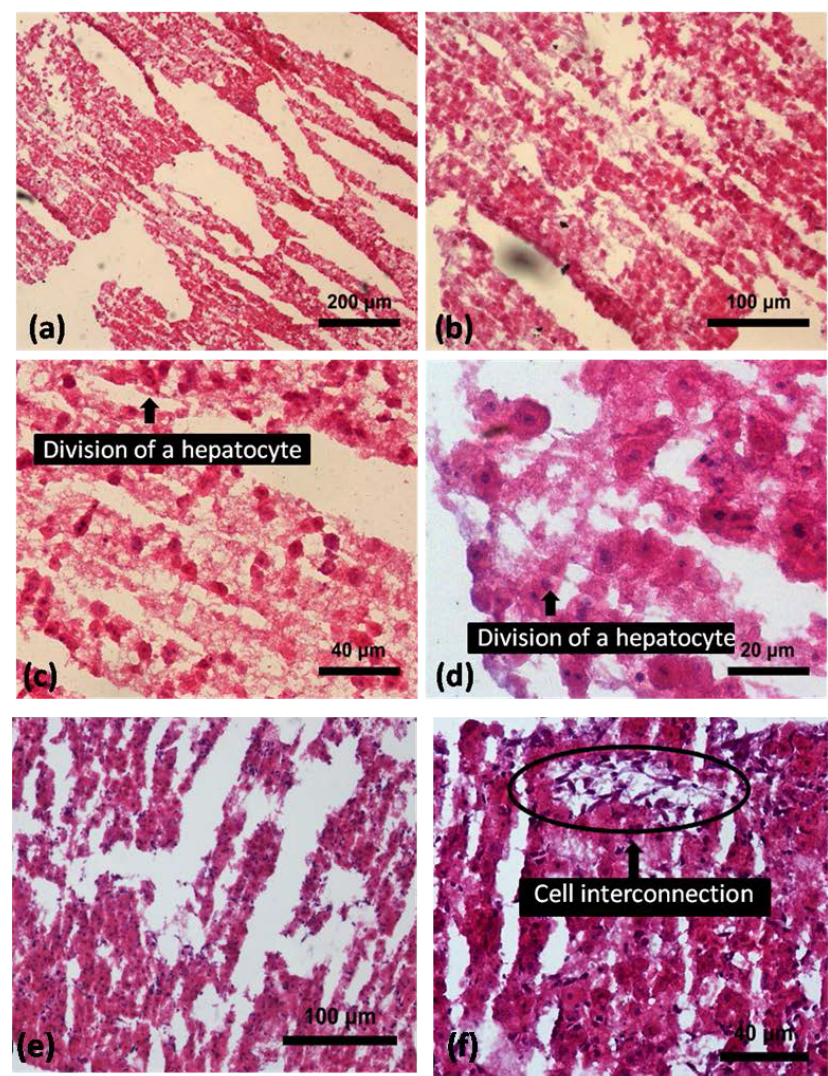

(d)
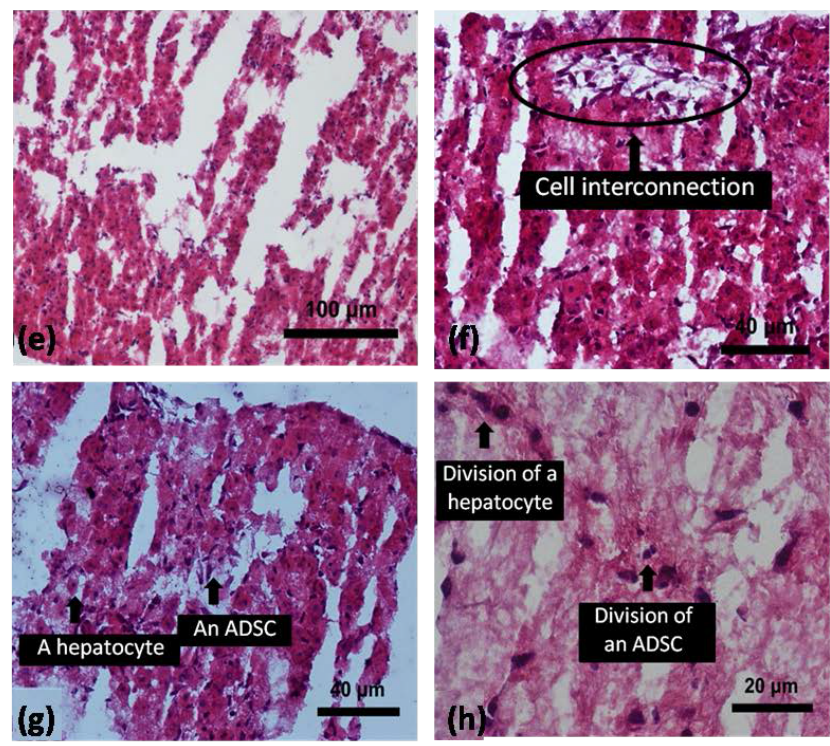

Figure 4: HE staining results of the 3D cell-laden gelatine/alginate/fibrin constructs after 7 days in vitro culture: (a)-(d) hepatocyte alone; (e)-(h) ADSC/ hepactocyte cocultures. (f) and (g) are magnifications of $(e)$, while $(h)$ is a magnification of $(\mathrm{g})$.

prevents them from interacting directly. These results are coincident with the SEM images (Figure 3).

DAPI/CFSE staining results of hepatocytes and ADSCs/ hepatocytes in the gelatin/alginate/fibrinogen hydrogel

Figures $5 \mathrm{a}$ and $5 \mathrm{~b}$ are DAPI and CFSE staining results of the 3D construct with only hepatocytes after 7 days culture. DAPI mainly dyes the nucleus and CFSE mainly the cytoplasm. A large number of actively dividing cells were observed from both the staining results, which indicate that the primary hepatocytes in the 3D construct had strong proliferation ability after 7 days in vitro culture. In order to distinguish hepatocytes and ADSCs under a confocal microscope, we applied CFSE to stain the hepatocytes and DAPI to the ADSCs. In Figures $5 \mathrm{c}$ and $5 \mathrm{~d}$ ADSCs/hepactocytes were normal cultured without the addition of drugs. Cell-cell interactions in between the hepatocytes are prevailing with a lot of threadlike structures. 


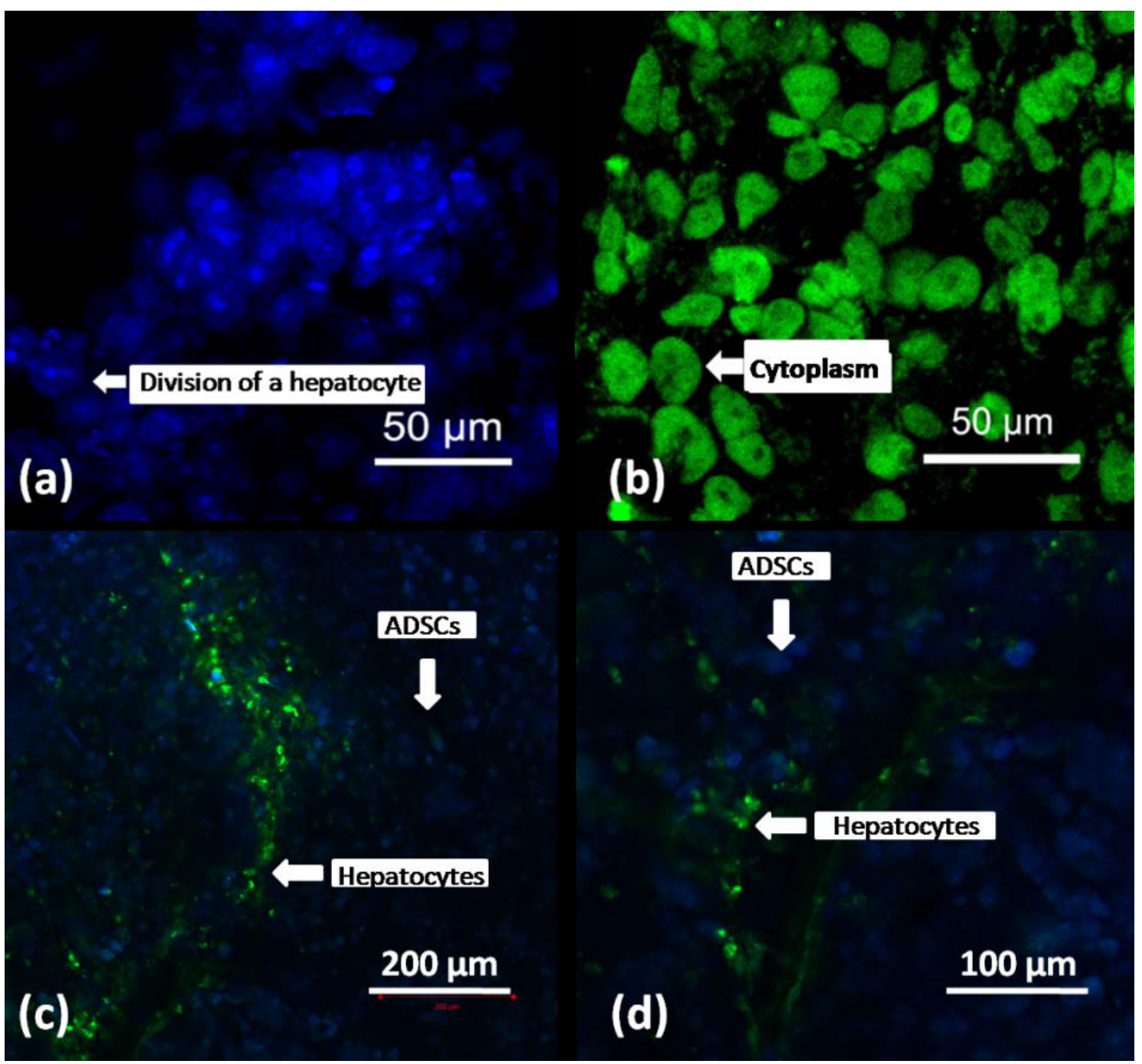

Figure 5: DAPI/CFSE staining results of the 3D cell-laden gelatine/alginate/fibrin constructs after 7 days in vitro culture. (a) and (b) hepatocytes only. (c) ADSC/ hepactocyte cocultures with interconnections among the cells. (d) is a magnification of (c).

\begin{tabular}{|c|c|c|c|c|c|c|c|c|c|}
\hline \multirow{2}{*}{$\begin{array}{c}\text { Culture type } \\
\text { Concentration Culture } \\
\text { time (d) }\end{array}$} & \multicolumn{3}{|c|}{ 2D } & \multicolumn{3}{|c|}{ 3D } & \multicolumn{3}{|c|}{ 3D coculture } \\
\hline & $\mathbf{H}$ & $\mathbf{M}$ & L & $\mathbf{H}$ & M & $\mathbf{L}$ & $\mathbf{H}$ & $\mathbf{M}$ & $\mathbf{L}$ \\
\hline 1 & 1.71 & 0.74 & 0.92 & 1.28 & 1.19 & 1.33 & 1.91 & 1.79 & 0.75 \\
\hline 2 & 1.57 & 0.99 & 0.88 & 0.77 & 1.13 & 0.79 & 1.97 & 1.98 & 1.02 \\
\hline 3 & 2.26 & 0.90 & 1.22 & 0.91 & 1.03 & 0.85 & 2.60 & 1.92 & 1.18 \\
\hline 4 & 1.75 & 0.50 & 1.00 & 1.08 & 1.24 & 1.44 & 2.78 & 2.23 & 1.21 \\
\hline
\end{tabular}

2D: Two-Dimensional; 3D: Three-Dimensional; H: High Concentration; M: Middle Concentration; L: Low Concentration

Table 2: Drug screening results (OD) of the astragalus polysaccharide.

\section{Drug screening results}

Table 2 contains the drug screening results (OD) of the AP, and Figure 6 shows the cell survival rates under different culture conditions after exposed to AP, 5-FU and matrine for 1 to 4 days. It was found that the culture conditions have significant effects on the drug screening results. AP shows cytotoxicity for the $2 \mathrm{D}$ hepatocyte cultures by reducing the cell survival rate by half, while the cell proliferation ability of the 3D hepatocyte cultures increases approximately $20 \%$. In the $3 \mathrm{D}$ coculture model, the hepatocyte number doubled after 4 days exposure to AP. Significant differences were found among the 2D, 3D, $3 \mathrm{D}$ coculture groups containing pure hepatocytes or ADSC/hepatocyte mixtures $(\mathrm{P}<0.05)$.

Figure 7 show that different concentrations of AP, 5-FU and matrine also have significant influence on the hepatocyte survival rates in the 3D model (pure hepatocytes). For AP, the highest difference appeared on the second day after drug medication. Cell survival rates of the high and the low concentration groups decreased by $20 \%$ while the survival rate of the middle concentration group decreased by $13 \%$. 
Significant differences were found among the three AP concentration groups containing pure hepatocytes $(\mathrm{P}<0.05)$.

Table 3 contains the drug screening results (OD) of the 5-FU. There is no significant difference between the 2D and 3D hepatocyte cultures after medicated by the 5-FU, indicating that the 5 -FU has little cytotoxicity to hepatocyte under the concentration of $50 \mu \mathrm{g} /$

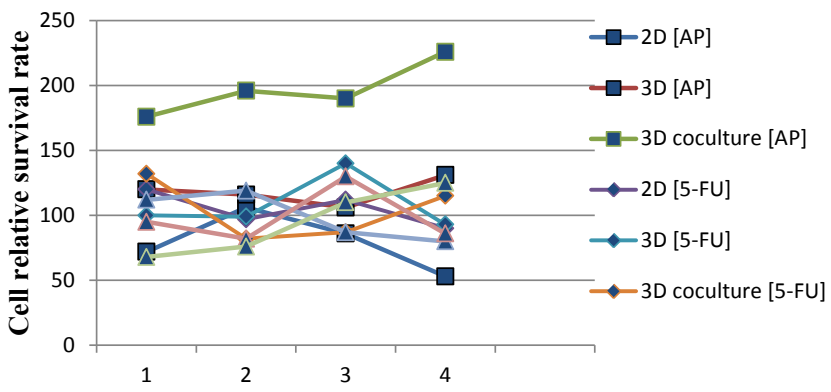

Figure 6: Cell relative survival rates of different culture models $(2 \mathrm{D}, 3 \mathrm{D}, 3 \mathrm{D}$ coculture) after medicated by middle concentration AP $(400 \mu \mathrm{g} / \mathrm{L}), 5-\mathrm{FU}(50$ $\mu \mathrm{g} / \mathrm{ml})$ and matrine $(0.15 \mathrm{mg} / \mathrm{ml})$ for 4 days. Significant differences were found among the $2 \mathrm{D}, 3 \mathrm{D}, 3 \mathrm{D}$ coculture groups containing pure hepatocytes or ADSC/ hepatocyte mixtures $(P<0.05)$.

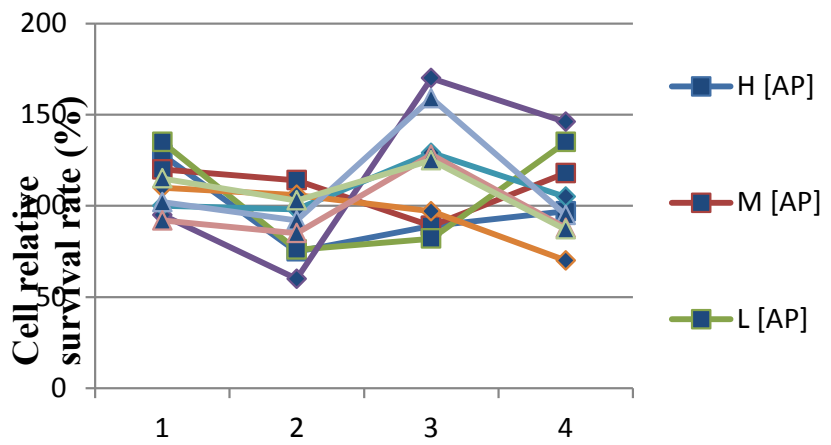

Figure 7: Cell relative survival rates of $3 \mathrm{D}$ model after medicated by AP, 5-FU and matrine with three different concentrations: high concentration $(H)$ AP $4 \mathrm{mg} / \mathrm{ml}$, 5-FU $500 \mu \mathrm{g} / \mathrm{ml}$, matrine $1.5 \mathrm{mg} / \mathrm{ml}$, middle concentration (M) AP $400 \mu \mathrm{g} / \mathrm{L}, 5-\mathrm{FU} 50 \mu \mathrm{g} / \mathrm{ml}$, matrine $0.15 \mathrm{mg} / \mathrm{ml}$, and low concentration (L) AP $40 \mu \mathrm{g} / \mathrm{L}, 5-\mathrm{FU} 5 \mu \mathrm{g} / \mathrm{ml}$, matrine $15 \mu \mathrm{g} / \mathrm{ml}$. Significant differences were found among the three different AP concentrations $(P<0.05)$. $\mathrm{ml}$. However, the survival rate of the ADSC/hepactocyte cocultures deceases sharply on the second day to $82 \%$, and slowly recovers by the end of the $4^{\text {th }}$ day. In Figure 7 the 5-FU concentrations have significant influence on the hepatocyte survival rate of the 3D model. In the low concentration group, the cell survival rate drops continuously from $116 \%$ to $59 \%$, while in the middle and high concentration groups the cell survival rate rebounds on the third day. It seems that the higher the used drug concentration, the more obvious is the rebound. These results indicate that the ADSC/hepatocyte cocultures are more likely to develop drug resistance even with the highest 5-FU concentration.

Table 4 contains the drug screening results (OD) of the matrine. During the first two days exposing the proliferation rate of the hepatocytes in the $2 \mathrm{D}$ cultures remained nearly the same. After 4 days culture, the cell survival rate drops to $\sim 80 \%$. The survival rate of the 3D hepatocyte cultures fluctuates during the drug action stage, and decreases to $\sim 86 \%$ after 4 days exposing. Matrine expresses little cytotoxicity for the 3D ADSC/hepactocyte cocultures on the first day, while the cell proliferation rate increases about $29 \%$ after 4 days exposing. Figure 7 also shows the survival rate of the hepatocytes in the 3D model after treated with matrine in different concentrations. The line shapes are similar which reflects that there are no significant differences among the drug concentrations.

Figure 8 is the AO/PI staining results of the $2 \mathrm{D}$ model after 7 days in vitro culture and 4 days medication with different anti-cancer drugs in middle concentration (AP $400 \mu \mathrm{g} / \mathrm{L}, 5-\mathrm{FU} 50 \mu \mathrm{g} / \mathrm{ml}$, matrine $0.15 \mathrm{mg} /$ $\mathrm{ml}$ ). Figure $8 \mathrm{a}$ is the non-drug-medication control with hepatocytes distributed uniformly on the petri dishes. Figure $8 \mathrm{~b}$ is a magnification of Figure $8 \mathrm{a}$, showing some hepatocytes in division period with two nuclei. Figure $8 \mathrm{c}$ represents the AP group and Figure $8 \mathrm{~d}$ is a magnification of Figure $8 \mathrm{c}$. Compared to the control group, cell density declined sharply. In Figures $8 \mathrm{c}$ and $8 \mathrm{~d}$, the cell membranes are severely damaged and the cells are stained to red. Figures $8 \mathrm{e}$ and $8 \mathrm{f}$ show the results of the 5 -Fu group with different magnifications. Figures $8 \mathrm{~g}$ and $8 \mathrm{~h}$ are the matrine group. After treated with 5-FU and matrine, the cell membranes of the hepatocytes were damaged to some extend and the nuclei were stained red. Though the cells were still complete, the number of double nuclei decreased, reflecting that the cell proliferation ability was weakened.

Figure 9 is the AO/PI staining results of the 3D hepatocyte cultures after 7 days in vitro culture and 4 days medication by the three anticancer drugs in middle concentration (AP $400 \mu \mathrm{g} / \mathrm{L}, 5$-FU $50 \mu \mathrm{g} / \mathrm{ml}$, matrine $0.15 \mathrm{mg} / \mathrm{ml}$ ). Figure $9 \mathrm{a}$ is a negative $3 \mathrm{D}$ control without the

\begin{tabular}{|c|c|c|c|c|c|c|c|c|c|}
\hline \multirow{2}{*}{$\begin{array}{c}\text { Culture type } \\
\text { Concentration Culture } \\
\text { time (d) }\end{array}$} & \multicolumn{3}{|c|}{ 2D } & \multicolumn{3}{|c|}{ 3D } & \multicolumn{3}{|c|}{ 3D coculture } \\
\hline & $\mathbf{H}$ & $\mathbf{M}$ & $\mathbf{L}$ & $\mathbf{H}$ & $\mathbf{M}$ & $\mathbf{L}$ & H & M & L \\
\hline 1 & 0.98 & 1.21 & 1.06 & 0.90 & 1.00 & 1.16 & 0.81 & 1.31 & 0.85 \\
\hline 2 & 1.97 & 0.95 & 0.94 & 0.64 & 0.97 & 1.07 & 0.73 & 0.82 & 0.99 \\
\hline 3 & 0.82 & 1.14 & 1.34 & 1.81 & 1.38 & 0.93 & 0.83 & 0.87 & 1.00 \\
\hline 4 & 1.11 & 0.85 & 0.71 & 1.37 & 0.92 & 0.99 & 0.98 & 1.10 & 1.35 \\
\hline
\end{tabular}

Table 3: Drug screening results (OD) of the 5-Fluorouracil.

\begin{tabular}{|c|c|c|c|c|c|c|c|c|c|}
\hline \multirow{2}{*}{$\begin{array}{c}\text { Culture type } \\
\text { Concentration Culture } \\
\text { time (d) }\end{array}$} & \multicolumn{3}{|c|}{ 2D } & \multicolumn{3}{|c|}{ 3D } & \multicolumn{3}{|c|}{ 3D coculture } \\
\hline & $\mathbf{H}$ & M & $\mathbf{L}$ & $\mathbf{H}$ & M & $\mathbf{L}$ & $\mathbf{H}$ & M & $\mathbf{L}$ \\
\hline 1 & 1.07 & 1.07 & 1.00 & 1.02 & 0.93 & 1.11 & 0.78 & 0.67 & 0.84 \\
\hline 2 & 0.95 & 1.17 & 1.33 & 0.94 & 0.85 & 1.01 & 0.84 & 0.74 & 0.95 \\
\hline 3 & 0.77 & 0.89 & 0.92 & 1.62 & 1.32 & 1.29 & 1.06 & 1.11 & 1.07 \\
\hline 4 & 1.35 & 0.80 & 0.86 & 1.03 & 0.86 & 0.87 & 1.33 & 1.29 & 1.41 \\
\hline
\end{tabular}

Table 4: Drug screening results (OD) of the matrine. 
Citation: Zhao X, Du S, Chai L, Xu Y, Liu L, et al. (2015) Anti-Cancer Drug Screening Based on a Adipose-Derived Stem Cell/Hepatocyte 3D Printing Technique. J Stem Cell Res Ther 5: 273. doi:10.4172/2157-7633.1000273

Page 7 of 10

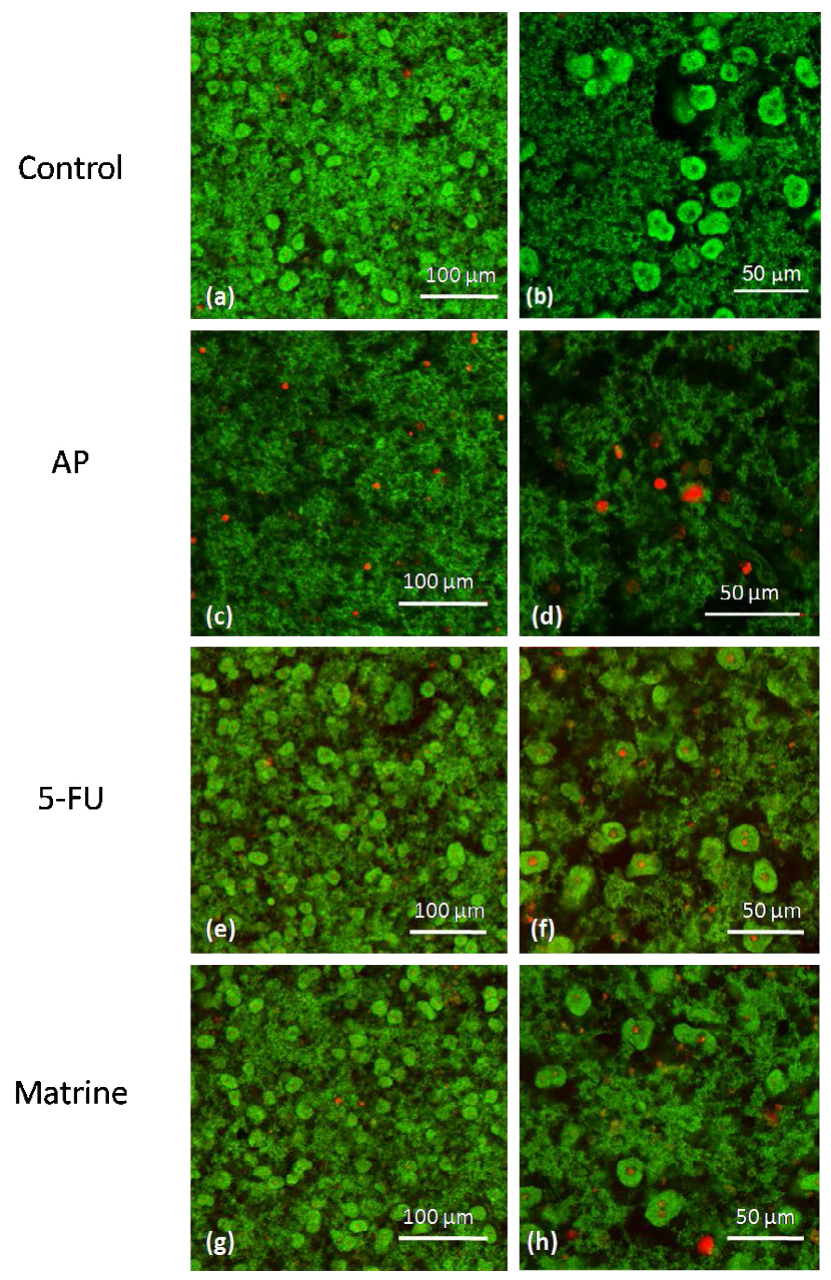

Figure 8: AO/PI staining of 2D hypatocyte cultures after in vitro drug (in middle concentration: AP $400 \mu \mathrm{g} / \mathrm{L}, 5-\mathrm{FU} 50 \mu \mathrm{g} / \mathrm{ml}$, matrine $0.15 \mathrm{mg} / \mathrm{ml}$ ) medication for 4 days. (a) is the control group and (b) is a magnification of (a). (c) (e) (g) are respectively the AP group, 5-FU group and matrine group. (d) (f) (h) are their magnifications.

use of the drugs. Compared to the drug used samples (Figures 9b-9d), hepatocytes inside the control group have a relatively high density. Especially, large cell aggregates are prominent. In a high magnification image (Figure 9b) the diameter of the cell clusters can reach $100 \mu \mathrm{m}$. Compared to the control group, the cell membrane of the drug used samples are greatly damaged (Figures $9 \mathrm{c}$ and $9 \mathrm{~d}$ for AP, Figures $9 \mathrm{e}$ and 9f for 5-Fu and Figures $9 \mathrm{~g}$ and $9 \mathrm{~h}$ for matrine). Meanwhile, the number of living cells declined sharply. The yellow color represents that the cells were damaged to dead with increased membrane permeability. These results indicate that the drugs have strong damage effects on the normal hepatocytes.

Figure 10 is the $\mathrm{AO} / \mathrm{PI}$ staining results of the $3 \mathrm{D}$ ADSC/hepactocyte coculture after 7 days in vitro culture and 4 days drug medication in middle concentration (AP $400 \mu \mathrm{g} / \mathrm{L}, 5$-FU $50 \mu \mathrm{g} / \mathrm{ml}$, matrine $0.15 \mathrm{mg} /$ $\mathrm{ml}$ ). With the addition of ADSCs in the gelatin/alginate/fibrin hydrogel, hepatocytes have a much stronger drug resistance than those in the only hepatocyte models. Interestingly, cell numbers in the 5-FU (Figures $10 \mathrm{e}$ and 10f) and matrine (Figures $10 \mathrm{~g}$ and $10 \mathrm{~h}$ ) used groups did not change obviously compared to the control group (Figures 10a and 10b). Especially, the number of cells in the AP used group doubled and the biggest cell cluster reaches $200 \mu \mathrm{m}$ in diameter, indicating that AP could enhance cell proliferation ability of the hepatocyte/ADSC cocultures.

\section{Discussion}

In vivo, single cells $(\sim 10 \mu \mathrm{m}$ in size $)$ extend to functional subunits $(\sim 100 \mu \mathrm{m}-1 \mathrm{~mm})$ and form hierarchical structures which coordinate tissue or organ functions. Over the last century, cells were isolated from tissues and cultured in 2D systems with neglected cell-cell and cell-matrix interactions. Previously, we have provided hepatocytes with microenvironments similar to the in vivo conditions with a series of $3 \mathrm{D}$ cell printing techniques $[10,11]$. In the present study, hepatocytes cultured in $2 \mathrm{D}$ and $3 \mathrm{D}$ environments were compared using MTT, CKK-8, HE, SEM, DAPI/CFSE and AO/PI methods. Generally, the 2D cultured cells adhere to the culture dishes with less interconnection. The $3 \mathrm{D}$ cultured cells gather together due to the cell migration and adhere to the EMCs, which is spatially more similar to the in vivo environment.

Primary hepatocytes appeared to be the most powerful liverspecific drug screening cell types [32]. Yet cell cocultures have

Control
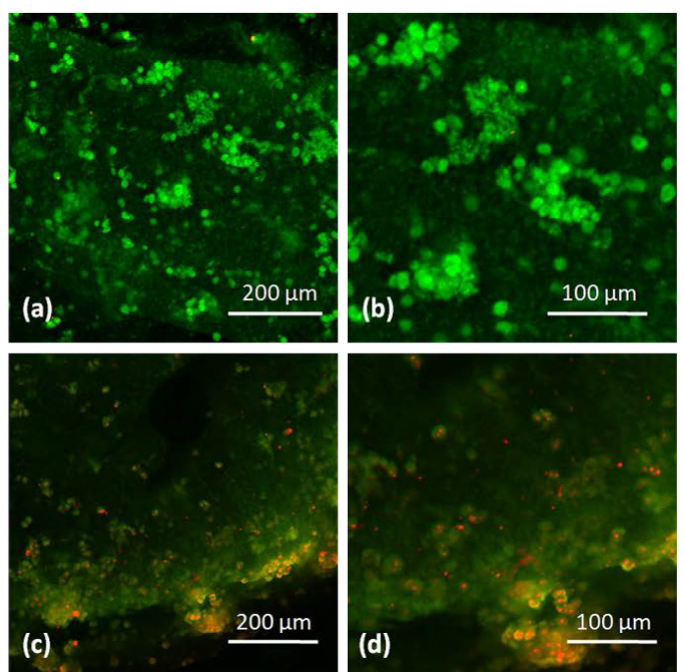

AP
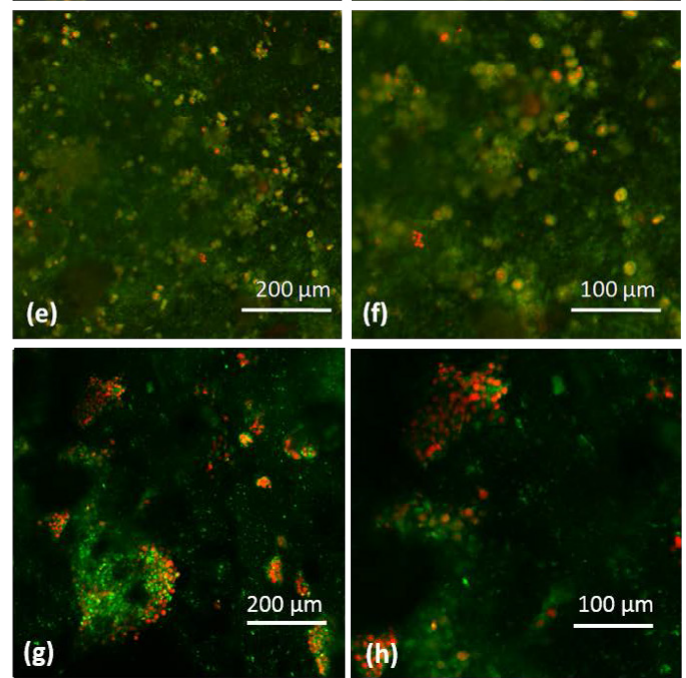

Figure 9: AO/PI staining of 3D hypatocyte cultures after in vitro drug (in middle concentration: AP $400 \mu \mathrm{g} / \mathrm{L}, 5-\mathrm{FU} 50 \mu \mathrm{g} / \mathrm{ml}$, matrine $0.15 \mathrm{mg} / \mathrm{ml}$ ) medication for 4 days. (a) is the control group and (b) is a magnification of (a). (c) (e) (g) are respectively the AP group, the 5-FU group and the matrine group. (d) (f) (h) are their magnifications. 


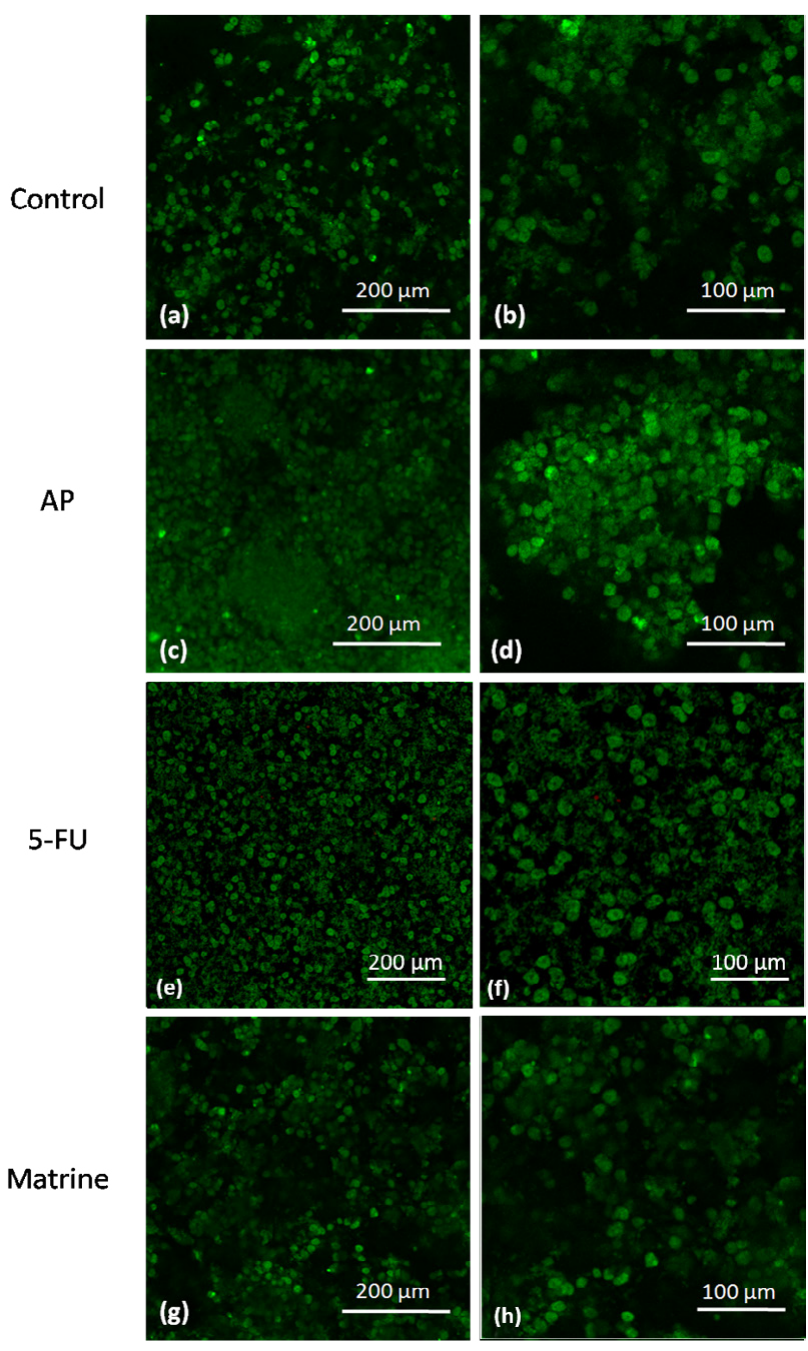

Figure 10: $A O / P I$ staining of $3 D$ ADSC/hepactocyte cocultures after in vitro drug (in middle concentration: AP $400 \mu \mathrm{g} / \mathrm{L}, 5-\mathrm{FU} 50 \mu \mathrm{g} / \mathrm{ml}$, matrine $0.15 \mathrm{mg} /$ $\mathrm{ml}$ ) medication for 4 days. (a) is the control group and (b) is a magnification of (a). (c) (e) (g) are respectively the AP group, the 5-FU group and the matrine group. (d) (f) (h) are their magnifications.

significant influence on hepatocyte functions. For example, Khetani [33] used semiconductor-driven micro-technology to fabricate a miniaturized, multi-cell culture system which maintains phenotypic functions of human hepatocytes for several weeks. Donato [34] found that mesenchymal stem cells (MSCs), an epithelial-derived cell line, improved the expression of drug biotransformation activities of cultured hepatocytes. In the present study, we supposed that ADSCs may have some effects on hepatocyte performance when these drugs are used. In the coculture group, cells seem to distribute more uniformly than in the pure hepatocyte group (Figures 9a and 10a) and they have different reactions to the three kinds of drugs (Figure 6).

In order to compare the drug screening results of the $2 \mathrm{D}$ and $3 \mathrm{D}$ cultures, a gelatin/alginate/fibrin hydrogel was used as a cell laden matrix. Gelatin is a kind of incomplete degradation or partially hydrolyzed protein. Its major component of polypeptide contains amino acid with favorable biodegradability and biocompatibility. Apart from that, gelatin also has moderate crosslink ability, adjustable solubility and excellent chemical properties [35]. Gelatin turns into colloid by reversible physical crosslink under $35^{\circ} \mathrm{C}$, which makes it useful in our cell printing systems.

Sodium alginate is a natural linear polysaccharide extracted from brown algae, made by $\beta$-D-mannuronic acid of $1-4$ bond and $\alpha$-Lguluronic acid with a formula of $\mathrm{C}_{6} \mathrm{H}_{7} \mathrm{O}_{6} \mathrm{Na}$. It has been used to replace damaged tissues and organs since early 1990s with relatively good biological compatibilities [36]. Alginate solution has a sol-gel transition with $\mathrm{Ca}^{2+}, \mathrm{Mg}^{2+}$ and other bivalent positive ions. With this property, it is easily to stabilize the $3 \mathrm{D}$ constructs with the crosslinking of the alginate molecules in the printed cell-laden filaments.

Fibrinogen is an important component to promote the blood coagulation. It is a precursor fiber protein synthesized by the liver and can be fully re-absorbed and replaced by the growing tissues. Fibrinogen is composed of $\alpha, \beta$ and $\gamma$ polypeptides, and its peptide chains are connected by disulfide bonds. Under the action of thrombin, $\alpha$ chain and $\beta$ chain release peptide $A$ and peptide $B$ to generate the fibrin monomer. The monomers are further polymerized by covalent bond and form stable fibrin clot to complete the coagulation process [37]. With the addition of fibrinogen in the gelatin/alginate hydrogel and polymerization process, the $3 \mathrm{D}$ constructs were further stabilized. The gelatin/alginate/fibrin hydrogel could act as an ECM for the encapsulated cells and provided the cells with an excellent growth microenvironment. After comparing the different hydrogel concentrations, we found that $10 \%(\mathrm{v} / \mathrm{w})$ gelatin is beneficial for micropore formation enabling the cells to migrate and proliferate inside.

There were two purposes for the series of biological characterizations. One is to observe the cell morphologies and the relationships among cells with the help of HE staining, SEM and DAPI/CFSE fluorescence labeling. The other is to assist the drug screening effects with the help of MTT, CCK-8, and AO/PI staining. DAPI and CFSE double staining were employed to distinguish the hepatocytes and ADSCs. DAPI is a fluorescence stain that can pass through the cell membrane and combine with the double chain DNA to emit purple fluorescence under fluorescence microscope. As no toxicity to cells, it is commonly used in apoptosis detection. CFSE can easily pass through the cell membrane and emit green fluorescence when combined with proteins of living cells. It has no toxicity to cells, and the fluorescence can be divided equally among the offspring. With the help of CFSE staining, it was easy for us to detect the cell proliferation states in the $3 \mathrm{D}$ constructs [38].

AP is one of the main active ingredients of astragalus, a kind of liver-protecting Chinese herbal medicine, obtained by high-tech extraction and separation. It consists of furonic acid, glucose, fructose, rhamnose, arabinose, galacturonic acid and glucuronic acid. AP can be used as immune promoter and regulator, and also has the effect of antiviral, anticancer, anti-aging, radiation resistance, stress resistance and oxidation resistance [39]. In the present study, AP enhanced the proliferation capabilities of the $3 \mathrm{D}$ cultured pure hepatocytes and ADSC/hepactocyte cocultures, while it weakened the activity of the $2 \mathrm{D}$ cultured hepatocytes (Figure 6). This phenomenon proved that the 3D construct printed by the cell assembly machine provided better living conditions for the hepatocytes than the $2 \mathrm{D}$ cultures.

5 -Fluorouracil is a common chemotherapy drug for many kinds of cancers. It blocks the synthesis of thymine, an essential raw material of DNA replication [40]. The higher the used concentration, the greater is the cytotoxicity it has in the first 2 days. But from the third day on, the survival rates were rebound (Figure 6). Matrine is an alkaloid extracted from the dried root, plant and fruit of sophora by organic solvents such as ethanol. It is used as anti-viral drug against hepatitis B and hepatitis 
C, and is recently found to have anti-tumorous effects [41]. It has cytotoxicity to both the 2D and 3D cultured hepatocytes. Nevertheless, cell survival rates in the 3D cocultures increased from $67 \%$ to $129 \%$ during the 4 days culture (Figure 6).

In the succinatedehydrogenase (SDH) staining method (CCK-8), soluble tetrazolium salt WST- 8 is used to reduce the soluble aurantius under certain conditions. CCK- 8 is a good colorimetric method for living cells, especially in cell proliferation and toxicity measurements [42]. The MTT colorimetric method can be used to detect the cell proliferation rate. The principle of the MTT colorimetric method is that mitochondrial succinate dehydrogenase can restore the exogenous MTT to insoluble blue purple crystal formazan and deposit it in cells. However, dead cells do not have this function. DMSO can dissolve the formazan in cells. By using enzyme-linked immune detectors we can measure its absorbance value at $\lambda s=490 \mathrm{~nm}$, which is a proxy of the number of living cells. Within a certain amount of cells, the number of MTT crystals is in direct proportion to the cell numbers $[43,44]$.

$\mathrm{AO}$ is a fluorescence dye with nucleic acid compatibility, and displays green color under fluorescence microscope. AO has membrane permeability, and has affinity with active DNA. It was difficult for AO to act with apoptotic cells due to the chromatin pyknosis or break. So AO staining was used to distinguish living cells and dead cells under fluorescence microscope. PI is also a nucleus staining material that can dye DNA with red fluorescence. Different from AO, PI cannot penetrate living cell membranes, and is generally used in the detection of cell apoptosis. By integrating AO and PI staining, the living and dead cells were distinguished under fluorescent microscope at the same time. After being exposed to drugs the membrane permeability of the cells changed and the nucleus of the dying cells were stained red (Figures 8 and 9). Yet in the coculture groups, most of the cell activities remained with hardly any red nucleus (Figure 10).

Similarly, we can clearly see the cell states in the $3 \mathrm{D}$ printed hepatocyte/ADSC cocultures using DAPI/CFSE double staining. In the control group (Figure 5), the cytoplasm of the hepatocytes and ADSCs were plump and the nuclei were complete. In the drug used groups different culture conditions had significant influences on the cell survival rates (Figure 6) and morphologies (Figures 8,9 and 10). Among the three anti-carcinogen drugs, astragalus had apoptosis inhibition ability on the hepatocyte, while 5-FU and matrine were toxic to the hepatocytes. Different drug concentrations also had obvious effects on cell proliferation rates (Figure 7) in the 3D models. Compared to the 2D cultures the $3 \mathrm{D}$ models enhanced the hepatocyte proliferation abilities to a certain degree when the anti-tumor drugs were used. Meanwhile, the $3 \mathrm{D}$ coculture had the highest cell proliferation rate among all experiment groups.

In addition, with our 3DP techniques, cells can be assembled in a $3 \mathrm{D}$ construct using the robotic printer in about $20 \mathrm{~min}$. The following sample handling and data processing can be manipulated repeatedly and quickly with the software control systems. Cells that are cultured in the $3 \mathrm{D}$ environments more closely mimic the tissues in the body than those grown in 2D. Consequently, the drug screening platform can be high-throughput, easily scalable and more reliable, which allows researchers to conduct genetic, chemical, or pharmacological tests.

\section{Conclusions}

A 3D drug screening model was created through a cell-laden gelatin/alginate/fibrinogen hydrogel printing technique developed by Tsinghua University. And a series of biological characterizations were carried out, including microstructures, cell proliferation abilities, and cell survival status. It was found that pure hepatocyte or ADSC/ hepactocyte mixtures were all in good conditions after 7 days culture with many cells in division states. The 3D construct provided cells with a good cell survival environment and was used to compare drug screening abilities with 2D cell culture and 3D coculture systems. Cells easily built connections in the 3D samples that contained a low gelatin concentration. In the ADSC/hepactocyte cocultures, hepatocyte and ADSCs could be distinguished by the staining color and size. After exposed to three anti-tumor drugs some of the cells were damaged with decreased proliferation rate and cell-cell interconnections. The AO/PI staining results were consistent with the MTT results. AP could inhibit the hepatocyte apoptosis to certain extent. 5-FU and matrine both had toxic effects on the hepatocytes. The toxic effect of the 5-FU was relatively stronger within the low concentration group. Compared to the $2 \mathrm{D}$ cultures the $3 \mathrm{D}$ constructs enhanced the drug-resistance ability of the hepatocytes to a certain degree, while the ADSC/hepactocyte cocultures had the highest cell proliferation rate.

\section{Aknowledgments}

The work was supported by grants from the Cross-Strait Tsinghua Cooperation Basic Research (No. 2012THZ02-3), Beijing Municipal Natural Science Foundation (No. 3152015), National Natural Science Foundation of China (NSFC) (No. 81271665 \& 30970748), International Cooperation and Exchanges NSFC and Japanese Society for the Promotion of Science (JSPS) (No. 81411140040), State Key Laboratory of Materials Processing and Die \& Mold Technology, Huazhong University of Science and Technology (No. 2012-P03), and the National High Tech 863 Grant (No. 2009AA043801).

\section{References}

1. Carnero A (2006) High throughput screening in drug discovery. Clin Transl Oncol 8: 482-490. [PubMed]

2. Horning JL, Sahoo SK, Vijayaraghavalu S, Dimitrijevic S, Vasir JK, et al. (2008) 3-D tumor model for in vitro evaluation of anticancer drugs. Mol Pharm 5: 849862. [PubMed]

3. Aikawa E, Nahrendorf M, Sosnovik D, Lok VM, Jaffer FA, et al. (2007) Multimodality molecular imaging identifies proteolytic and osteogenic activities in early aortic valve disease. Circulation 115: 377-386. [PubMed]

4. Arnold CB, Serra P, Piqué A (2007) Laser Direct-Write Techniques for printing of complex materials. MRS Bulletin 32: 23-29.

5. Hull C, Feygin M, Baron Y, Sanders R, Sachs E, et al. (1995) Rapid prototyping current technology and future potential. Rapid Prototyping Journal 9: 11-19.

6. Wang X, Zhang Q (2011) Overview on "Chinese-Finnish workshop on biomanufacturing and evaluation techniques. Artif Organs 35: E191- E193. [PubMed]

7. Wang X, Tuomi J, Mäkitie AA, Paloheimo K-S, Partanen J, et al. (2013) The integrations of biomaterials and rapid prototyping techniques for intelligent manufacturing of complex organs. InTech: Rijeka, Croatia.

8. Wang X, Yan Y, Zhang R (2010) Gelatin-based hydrogels for controlled cel assembly. Springer, New York.

9. Lee W, Debasitis JC, Lee VK, Lee JH, Fischer K, et al. (2009) Multi-layered culture of human skin fibroblasts and kerainocytes through three-dimensional freeform fabrication. Biomaterials 30: 1587-1595. [PubMed]

10. Cohen DL, Malone E, Lipson H, Bonnssar LJ (2006) Direct freeform fabrication of seeded hydrogel in arbitrary geometries. Tissue Eng 12: 1325-1335. [PubMed]

11. Wang X, Yan Y, Pan Y, Xiong Z, Liu H, et al. (2006) Generation of threedimensional hepatocyte/gelatin structures with rapid prototyping system. Tissue Eng 12: 83-90. [PubMed]

12. Yan $Y$, Wang $X$, Pan Y, Liu H, Cheng J, et al. (2005) Fabrication of viable tissueengineered constructs with $3 \mathrm{D}$ cell-assembly technique. Biomaterials $26: 5864$ 5871. [PubMed]

13. Li S, Xiong Z, Wang X, Yan Y, Liu H, et al. (2009) Direct fabrication of a hybrid cell/hydrogel construct by a double-nozzle assembling technology. J Bioact Compat Polym 24: 249-264. 
Citation: Zhao X, Du S, Chai L, Xu Y, Liu L, et al. (2015) Anti-Cancer Drug Screening Based on a Adipose-Derived Stem Cell/Hepatocyte 3D Printing Technique. J Stem Cell Res Ther 5: 273. doi:10.4172/2157-7633.1000273

Page 10 of 10

14. Li S, Yan Y, Xiong Z, Wang C, Zhang R, et al. (2009) Gradient hydrogel construct based on an improved cell assembling system. J Bioact Compat Polym 24: 84-99

15. Yao R, Zhang R, Yan $Y$, Wang $X(2009)$ In vitro angiogenesis of $3 D$ tissue engineered adipose tissue. J Bioact Compat Polym 24: 5-24.

16. Yao $R$, Zhang $R$, Wang $X$ (2009) Design and evaluation of a cell microencapsulating device for cell assembly technology. J Bioact Compat Polym 24: 48-62.

17. Wang X, Xu H (2010) Incorporation of DMSO and dextran-40 into a gelatin/ alginate hydrogel for controlled cell cryopresergation. Cryobiology 61: 345-351. [PubMed]

18. Wang X, Paloheimo KS, Xu H, Liu C (2010) Cryopreservation of cell/hydrogel constructs based on a new cell-assembling technique. J Bioact Compat Polym 25: 634-653.

19. Sui S, Wang X, Liu P, Yan Y, Zhang R (2009) Cryopreservation of 3D constructs based on a controlled cell assembling technology. J Bioact Compat Polym 24: 473-487.

20. Xu W, Wang X, Yan Y, Zheng W, Xiong Z, et al. (2007) Rapid prototyping of three-dimensional cell/gelatin/fibrinogen constructs for medical regeneration. $J$ Bioact Compat Polym 22: 363-377.

21. He K, Wang X (2011) Rapid prototyping of tubular polyurethane and cell/ hydrogel construct. J Bioact Compat Polym 26: 363-374.

22. Huang $Y$, He K, Wang $X$ (2013) Rapid Prototyping of a hybrid hierarchical polyurethane-cell/hydrogel onstruct for regenerative medicine. Mater Sci Eng C Mater Biol Appl 3: 3220-3229. [PubMed]

23. Zhao X, Liu L, Wang J, Xu Y, Zhang W, et al. (2014) In vitro vascularization of a combined system based on a 3D printing technique. J Tissue Eng Regen Med. [PubMed]

24. Zhao X, Wang X (2013) Preparation of an adipose-derived stem cell/fibrinpoly(DL-lactic-co-glycolic acid) construct based on a rapid prototyping technique. J Bioact Compat Polym 28: 191-203.

25. Wang X, He K, Zhang W (2013) Optimizing the fabrication processes for manufacturing a hybrid hierarchical polyurethane-cell/hydrogel construct. J Bioact Compat Polym 28: 303-319.

26. Wang X, Cui T, Yan Y, Zhang R (2009) Peroneal nerve regeneration along a new polyurethane-collagen guide conduit. J Bioact Compat Polym 24: 109-127.

27. Wang X, Yan Y, Zhang R (2007) Rapid prototyping as a tool for manufacturing bioartificial livers. Trends Biotechnol 25: 505-513. [PubMed]

28. Wang $X$ (2012) Intelligent freeform manufacturing of complex organs. Artif Organs 36: 951-961. [PubMed]
29. Wang X, Yan $Y$, Zhang $R$ (2010) Recent trends and challenges in complex organ manufacturing. Tissue Eng Part B 16: 189-197. [PubMed]

30. Wang $X$ (2014) Spatial effects of stem cell engagement in 3D printing constructs. J Stem Cells Res Rev \& Rep 1: 5-9.

31. Xu Y, Wang $X(2015)$ 3D biomimetic models for drug delivery and regenerative medicine. Curr Pharm Des 21: 1618-1626. [PubMed]

32. Liu L, Zhou X, Xu Y, Zhang W, Liu CH, et al. (2015) Controlled release of growth factors for regenerative medicine. Curr Pharm Des 21: 1627-1632. [PubMed]

33. Guillouzo A (1998) Liver cell models in in vitro toxicology. Environmental Health Perspectives 106: 511-531

34. Khetani SR, Bhatia SN (2008) Microscale culture of human hepatocytes for drug development. Nat Biotechnol 26: 120-126. [PubMed]

35. Donato MT, Castell JV, Gónez-Lechón MJ (1991) Cocultures of hepatocytes with epithelial-like cell lines: Expression of drug-biotransformation activities by hepatocytes. Cell Biol Toxicol 7: 1-44. [PubMed]

36. Vert M (2005) Aliphatic polyesters: great degradable polymers that cannot do everything. Biomacromolecules 6: 538-546. [PubMed]

37. Piskin E (1995) Biodegrdable polymers as biomaterials. J Biomater Sci Polym Ed 6: 775-795. [PubMed]

38. Lee YJ, Braun PV (2003) Tunable inverse opal hydrogel PH sensors. Advanced Materials 5: 563-566.

39. Boxella A, Hijjawi N, Monisc P, Ryan U (2008) Comparison of various staining methods for the detection of Cryptosporidium in cell-free culture. Exp Parasito 120: 67-72. [PubMed]

40. Xiong JW, Xiao H, Zhang ZX (2007) An experimental research on different detection conditions between MTT and CCK-8. Acta Laser Biology Sinica 16: $559-562$.

41. Pullarkat ST, Stoehlmacher J, Ghaderi V, Xiong YP, Ingles SA, et al. (2001) Thymidylate synthase gene polymorphism determines response and toxicity of 5-FU chemotherapy. Pharmacogenomics J 1: 65-70. [PubMed]

42. Cheng XD, Du YA, Huang L, Zheng ZG, Jing ZM (2008) The effect of matrine on $\mathrm{GSH}$ regulation and cytotoxicity in human hepatoma Hep G2 cells. China Cancer 17: 311-313.

43. Zhao LH, Li Q, Lin P, Lin P, Li K, et al. (2005) Cytotoxicity of astragalus polysaccharides combined with cisplatin of human BEL-7404 hepatoma combined with cisplatin on tumour cells. The Practical Journal of Cancer 20: 34-35.

44. Simper D, Stalboerger PG, Panetta CJ, Wang S, Caplice NM (2002) Smooth muscle progenitor cells in human blood. Circulation 106: 1199-1204. [PubMed] 